\title{
The Role of Risk Perception and Collaborative Management in Explaining Stringent Municipal Regulations - The Israeli Air Pollution Case Study
}

Dorit Kerret*, Gila Menahem and Shira Frishberg

The Department of Public Policy, Aviv University, Israel

"The Authors contributed equally to this paper

\begin{abstract}
What influences municipalities to proactively enact more stringent environmental standards relative to the central state's stipulated requirements? What is the role of environmental need (risk) in determining the level of action? And what is the relationship between objective risk indicators and subjectively perceived ones? Does Collaborative Management (CM) at the local level influence the stringency of local environmental legislation? This paper employs SEM analysis combining survey data from all municipalities in Israel with an analysis of local bylaws to address these questions. Doing so enables us to contribute the following insights to the research literature. First, we add to the thin extant literature on the role of municipalities in addressing environmental problems and construct a model of factors affecting stringent environmental regulation. Second, the study extends the very small number of nonUS studies regarding environmental outputs in municipalities. Third, our study answers the call to investigate conditions under which $\mathrm{CM}$ enhances environmental achievements. Fourth, the study further contributes to understanding the importance of perceived risk for explaining local environmental policies and how they are influenced by $\mathrm{CM}$. The results demonstrate the important role of both perceived risk and $\mathrm{CM}$ in influencing the stringency of local environmental regulation.
\end{abstract}

Keywords: Environmental standards; Collaborative management; Stringent municipal regulations

\section{Introduction}

What influences municipalities to proactively enact more stringent environmental standards relative to the central state's stipulated requirements and prevents a potential race to the bottom? What is the role of environmental need (risk) in determining the level of action? And what is the relationship between objective risk indicators and subjectively perceived risk in impacting environmental standards? Finally, do local policy processes have impact on environmental standards? And more specifically, does Collaborative Management $(\mathrm{CM})$ at the local level influence the stringency of local environmental legislation?

These questions lie at the center of this article, and are of both theoretical and practical importance. The role of local actors in advancing environmental policy has recently been acknowledged [14] and much progress has been made in disentangling the variables affecting state legislatures' environmental policies in the US [2]. Attention has also been paid to the important role of municipalities in promoting sustainability practices, [5] mainly focusing on combating GHG emissions [6-8]. At the same time the role of municipalities in environmental regulation has also traditionally been related to an inherent threat of a race to the bottom $[9,10]$. This paper focuses on the role of municipalities in enhancing environmental requirements in air pollution issues through local legislation and on explaining which factors contribute to more stringent local regulation as opposed to potential race to the bottom. The legislative power of municipalities in environmental matters is particularly important due to the potential connection between stringent local environmental regulation and environmental outcomes [11].

This paper addresses two important aspects regarding the factors affecting regulatory stringency in municipalities. First, the role of "problem severity" as an explanatory factor for regulatory stringency is discussed. Contradictory results regarding the role of problem severity in explaining environmental policy efforts have been observed in the literature [12]. The following study suggests that one important aspect in this regard that should be addressed and has not been adequately dealt with is the gap between objective problem severity and problem severity as perceived by policy makers. Second, the role of CM in influencing municipalities to enact stringent regulations is discussed. $\mathrm{CM}$ recently emerged as one of the policy processes impacting performance in various policy domains $[13,14]$.

The role of municipalities in environmental regulation has traditionally been related to an inherent threat of a race to the bottom $[9,10]$. The Israeli context offers a unique and interesting opportunity to examine these theoretical questions. First it offers a context for unraveling factors that may contribute to mitigating and even offsetting the potential threat of race to bottom of local legislation. This opportunity lies in the nature of the Israeli regulatory context at the time the study was conducted. Local governments were granted the discretion to decide whether they would like to enact more stringent local bylaws, relax them or leave them at the national standards level. Our study focuses on the role of CM in mitigating the race to the bottom and enhancing the tendency to enact more stringent local bylaws.

The present article addresses these points through a study of all urban municipalities in Israel. Our aims in conducting this study are to contribute to current research in the

\section{Following ways:}

- Our study adds to the thin extant literature on the role of municipalities in addressing environmental problems that are not necessarily GHG related and constructs a model of factors affecting stringent environmental regulation.

*Corresponding author: Kerret D, The Department of Public Policy, Aviv University, P.O.B.39040, Tel-Aviv 69978 Ramat-Aviv, Israel, Tel: 97236409516 Fax: 97236407382; E-mail: doritk@post.tau.ac.il

Received June 17, 2015; Accepted July 24, 2015; Published July 27, 2015

Citation: Kerret D, Menahem G, Frishberg S (2015) The Role of Risk Perception and Collaborative Management in Explaining Stringent Municipal Regulations The Israeli Air Pollution Case Study. Review Pub Administration Manag 3: 157 doi:10.4172/2315-7844.1000157

Copyright: (C) 2015 Kerret D, et al. This is an open-access article distributed under the terms of the Creative Commons Attribution License, which permits unrestricted use, distribution, and reproduction in any medium, provided the original author and source are credited. 
- The study answers the call to investigate conditions under which CM enhances environmental achievements [15] and enhances the very small number of large $N$ studies regarding the consequences of CM [16].

- The study further contributes to understanding the importance of perceived risk for explaining local environmental policies and how they are influenced by CM [17].

- The study extends the very small number of non-US studies regarding environmental outputs in municipalities, using SEM analysis [9].

Our article proceeds in the following manner: Theoretical considerations regarding the impact of risk perception and $\mathrm{CM}$ on local environmental bylaws are offered. Following the main characteristics of the role of municipalities in combating air pollution in Israel are presented. Presentation of the empirical findings of the study is followed by discussion of the findings.

\section{Factors affecting environmental policy-theory and hypotheses}

Risk perceptions and objective risk: The severity of environmental problems was identified as one group of factors influencing comparative environmental outputs and outcomes on the state level [2]. Referred to as the matching perspective, the argument contends that states match the stringency of their environmental policies to the scope of their pollution problems [4]. In this line, Meyer and Konisky found that environmental need plays a strong role in community adoption of local environmental institutions [18]. However, evidence regarding the effect of problem severity upon policy adoption is still contradictory [12]. Zahran et al., for example, found no evidence that climate change risk influences the prevalence of cities becoming members of international environmental organizations in metro areas [8].

Some of the inconsistencies in the effect of environmental need on environmental outcomes and outputs might be influenced by the gap between objective measures of environmental problems and policy makers' risk perceptions. Risk analysis literature acknowledges the gap between scientifically calculated risk and risk perceptions [17]. Determining environmental risk is a complicated task that requires a high level of technical knowledge. Nevertheless, it generally leaves much room for uncertainty and discretion regarding the level of acceptable risk. Furthermore, it has been shown that laypersons' considerations in determining environmental risk and its acceptability level differ from those of scientists, often as a result of information asymmetry and complexity [19]. As a result, the perceptions of risk, and not only objective risk measurements, play an important role in policy considerations.

Understanding that risk perceptions are affected by various stakeholders sharing information is compatible with the wide literature that deals with the processes of problem definition in public policy [20-22]. The public policy literature contends that understanding of the nature of social problems is not directly derived from objective examination of the existing situation. Rather, it is shaped in a process of framing and reframing that takes place in the policy discourse and involves individuals and groups interested in the definition of the nature of the problem [22-27].

Stone asserts that the process of problem definition includes building a causal story about the problem, its sources, its severity and its potential solutions Definitions of problems and causal stories convey shared meanings about the severity of the risk situation. These perceptions are carried into decision making processes [28].
The notion of a potential gap between objectively measured risk and risk perception is also compatible with the alternative approaches to the performance movement proposed by Radin (Radin, 2006). Radin contends that information cannot be neutral, because it is affected by beliefs, values and agendas. "One actor's "fact" is another actor's "value" [29].

This line of reasoning suggests that shared meanings and perceptions regarding risk severity play an important role in policy decisions and may have a more pronounced impact than objectively measured risk indicators. Indeed the importance of the perceptions of policy makers rather than objective facts has been acknowledged in previous literature as having important influence on policy outcomes $[10,30]$. As ultimately the stringency of local air pollution bylaws is determined by actors in the municipality, we assume that the risk as perceived by such actors will be a better predictor of the stringency of local bylaws than objective measures. Thus, our first hypothesis posits the following:

H1: Perceived risk will be a better determinant of the stringency of local air bylaws in comparison with objective risk

The role of collaborative management (CM): Furthermore, following the impact of idea sharing and stakeholders' involvement on risk perceptions, we assume that risk perceptions of local officials are determined by a combination of objective risk measures on the one hand and influences from stakeholders with whom they network or are exposed to on the other hand. The industrial sector for example represents such stakeholders with whom policy makers interact and NGOs represent a different set of such stakeholders to whom policy makers are exposed. Hence, a policy process that enhances interaction with such stakeholders will directly affect risk perceptions. More specifically, we refer to $\mathrm{CM}$ as a process enabling idea sharing among various stakeholders. By $\mathrm{CM}$, we mean "governments connecting with other governments and with the nongovernmental sector [...] managers and public and private agencies [in which they] jointly develop strategies and produce goods and services on behalf of their organizations" [13].

We suggest it is useful to view $\mathrm{CM}$ as promoting the emergence of collaborative forums, where stakeholders representing differing interests and orientations are exposed to the variety of viewpoints and interests and engage in a deliberative process. This notion is based on the distinction suggested by Schmidt and Radealli and Risse between "arguing" and "bargaining" and between "arenas" and "fora" [31,32] "Arguing" denotes deliberation that takes place in fora where individuals interact to generate ideas and develop common understandings. These ideas feed the arenas, where policy actors who have the power to formulate policy engage in a coordinative discourse ("bargaining"). We suggest that $\mathrm{CM}$ consists of forums where deliberation over environmental policy issues among differing or competing stakeholders takes place. Ideas and perceptions of environmental risks, and causal stories [22] that include paths for dealing with the risks, emerge in these contexts [33]. Hence, it is plausible that collaborative forums that include a variety of stakeholders discussing environmental risks and their meaning will impact policy makers' perceptions of the risks. By working collaboratively, stakeholders with different views and conflicting interests may understand the points of view of their counterparts and reach joint modes of operation beneficial to the environment [34]. Hence, CM has the potential to affect information perception or risk perception of relevant stakeholders $[17,18,29]$. 
We further suggest that $\mathrm{CM}$ has a more central role when the policy action considered is voluntary and yet may bear costs for some stakeholders. Crafting more stringent air bylaws requires the motivation of policy makers to act proactively and change the status quo (i.e. national legislation). While such action may have beneficial environmental outcomes, it also bears costs at least on some of the important actors in the locality, such as the local industry. We suggest that $\mathrm{CM}$ enables policy makers to take such actions through its impact on risk perceptions. CM creates a platform for local actors to raise their concerns about the levels of environmental risk and the need for action.

Thus, as CM enables different stakeholders to take part in shaping risk perceptions of local policy makers, our second hypothesis posits the following:

\section{H2A: CM will indirectly positively affect the stringency of local air bylaws through its effect on risk perceptions}

The Role of NGOs and CM: NGOs' activity has been widely acknowledged in the literature as having the potential to directly promote sustainable policies in municipalities [8,9,35,36]. At the same time, the relationships between green NGOs and local political decision makers have been fraught with conflict, as political elites do not always see eye to eye with NGOs with regard to the public interest. Pro-growth policies versus sustainable preservation and future generation orientation are examples of the gulf between NGOs and local political elites, a difference that impairs NGOs' attempts to advance environmental policies. NGOs in most cases constitute an "outside" actor compared to residents who are voters and taxpayers or industry that is a major source of employment and tax. Hence, often there may not be any clear interest of the local authority to take NGOs views into account. A collaborative style of management that includes NGOs offers a venue for them to influence policy makers, and studying the effect of CM on NGOs' impact on policy outputs is of much interest. The above discussed attributes of CM that allow various and contending stakeholders, including NGOs, to exchange viewpoints and develop common understandings make CM a potential factor that may impact the extent to which NGOs' activity affects policy makers' perceptions of environmental risks. Hence, we propose that the role of NGOs on risk perception and thus indirectly on environmental regulation is mediated by $\mathrm{CM}$.

Thus, our third and final hypothesis states:

\section{H2B: CM will mediate the influence of NGOs on risk perception}

The context of the study: Local regulation and the role of municipalities in combating air pollution in Israel Environmental policy in Israel developed quite late in terms of institutional structure $[37,38]$ and was perceived solely as the responsibility of the Ministry of Environmental Protection [38,39]. Municipalities were not considered to be major players in environmental protection. This focus led to a somewhat incoherent situation where on the one hand they were not provided with significant regulatory power in this regard [40], yet on the other hand legislation enabled them to enact local environmental bylaws that could be either more stringent or more relaxed than national air pollution control legislation. The authority within the municipality to enact local bylaws was given to the city council, which is an elected body that represents local residents (Attorney General Guidelines, 1985). Implementation of this regulatory power was voluntary, as municipalities were not obligated to enact such legislation. This situation existed until 2011, including the period when the study was conducted in 2008 .
Studying the implementation of this regulatory privilege that Israeli municipalities enjoyed up to 2011 could enlighten us regarding factors that might affect municipal environmental regulatory behavior. Since municipalities are allowed to either relax or strengthen regulations, we might have some information regarding race to the top or race to the bottom in local environmental legislation. The study focuses on the factors contributing to race to the top, that is, the number of local regulations that are more stringent than national law, since, interestingly, out of 159 municipalities that enacted local air pollution regulations only one locality used this power to relax one specific clause.

The study compares the regulatory instructions in local environmental legislation with existing national environmental air pollution prevention legislation. Generally, the stringent prescriptions in local legislation were focused on environmental monitoring and reporting requirements and some set more strict ambient standards. Examples of more stringent requirements include, among others, a requirement that industrial facilities have continuous monitoring of their emissions, while the national regulation only required a yearly monitoring; a more complete list of pollutants in comparison to the national regulation; providing authority to the head of the locality to instruct the manager of the facility to take steps to reduce pollution; and granting the locality the authority to eliminate a nuisance and charge the facility for the expenses.

\section{Methodology}

\section{Population}

The data is based on a survey of all municipalities in Israel. A total of 170 municipalities (hereinafter municipalities) within Israel's international borders were approached to assist in an academic study regarding "local municipalities and the environment." A double page questionnaire was sent to each locality's office. Municipalities that did not respond within two weeks were approached two additional times. Ultimately, 122 municipalities responded, producing an approximately $73 \%$ response rate. In most cases, the head of the local environmental department completed the questionnaire.

\section{Dependent variable}

Stringent local air pollution bylaws (SLAB): The dependent variable was constructed to measure the stringency of municipal regulations relative to national regulations. We compared national air requirements in national legislation to the local bylaws in all the municipalities (in total 304 bylaws), as elaborated above. Hence, we used a count of the number of requirements in municipal regulations that were more stringent than national regulations.

\section{Independent Variables}

Severity of environmental problem: We employed two separate indicators, subjective and objective, to measure the severity of environmental problems.

\section{Subjective Perceived Risk}

We employed local officials' perception of industrial air pollution as an environmental problem in their municipalities. The variable represents the respondents' answers to the question whether or not industrial air pollution was an environmental problem in their locality.

Objective risk indicator-Number of polluting facilities in the locality: Following Potoski and Woods, we accounted for the number of polluting sources as an objective measure of the severity of local environmental hazards [4]. We extracted data on the number 
Citation: Kerret D, Menahem G, Frishberg S (2015) The Role of Risk Perception and Collaborative Management in Explaining Stringent Municipal Regulations - The Israeli Air Pollution Case Study. Review Pub Administration Manag 3: 157. doi:10.4172/2315-7844.1000157

of industrial facilities in each locality by means of the Israeli Industry Association database.

CM: Following O'Toole and Meier [14,41] and Agranoff and McGuire, Agranoff and McGuire [13] this study conceptualized CM, in regard to environmental management issues, as the linkages and contacts of public actors with other public agencies and levels, as well as with non-public actors. While a count of contacts and types of contacts may seem to constitute imperfect measures of CM, McGuire [3,42] suggested that such measures have been shown to be adequate proxies for CM research and were used especially in large $\mathrm{N}$ studies [14]. We adopted McGuire's approach in this study and measured collaboration as the number of contacts, as proxy for CM.

To measure CM, municipalities were asked if collaboration on environmental issues had taken place with the following parties: Ministry of Environmental Protection, industry, residents, green NGOs, neighboring municipalities or other parties (specified). The $\mathrm{CM}$ variable was constructed by adding the number of collaborative activities of each locality.

Extent of Green NGOs' activity within the locality: This variable was used to ascertain the extent of the activity of NGOs. Municipalities were asked "How do you estimate the extent of the activity of environmental NGOs in your locality?" Respondents chose one of three options: "the activity is very noticeable"; "the activity is slightly noticeable"; or "the activity is not noticeable."

\section{Independent control variables}

We sought to control for the effect of the main intervening factors described in the literature when testing the connections among risk indicators, CM and SLAB. The control variables were chosen in accordance with the extant literature as follows.

Existence of an environmental unit in the locality: We introduced an organizational factor in order to account for the capacity of the locality as one of the additional factors that might affect outputs of the locality $[4,11]$. The main official body assigned responsibility for environmental issues in local authorities in Israel is the "Environmental Unit." According to the descriptive findings, only $68 \%$ of municipalities have an environmental unit. Hence, we refer to the existence of an environmental unit as an indicator of administrative capacity, as it employs professional staff whose primary responsibility is environmental policy within the locality. Data regarding the organizational structure of the environmental unit in each locality was obtained from the Israeli Ministry of Environmental Protection.

Socioeconomic grading of municipalities (SER): Previous research pointed to the role of socio-demographic and economic characteristics of the locality as having an impact on local governmental outputs in general and the pursuit of environmental policies in particular $[4,11,43,44]$. We used the Socio-Economic Grading of Municipalities in Israel that is computed and periodically updated by the Central Bureau of Statistics (CBS). The CBS classifies all Israeli urban municipalities using a composite scale of 17 selected socio-demographic characteristics (e. g., income-support recipients, unemployment, residents earning more than twice the average wage, average earnings per capita, average years of education). Municipalities are then assigned to a decile cluster (Eshkol in Hebrew) ranging from 10 (highest) to 1 (lowest), based on their individual scores on the composite scale. This classification is used here to operationalize the independent variable "socioeconomic rank" for each locality included in the study.
Percentage of educational expenses out of all expenses: As another indicator of economic and administrative capacity of the municipalities, we used the percentage of educational expenses out of all expenses for each locality, as computed and periodically updated by the CBS. Previous research has shown that in Israel educational expenses are a matter of policy choice and are not necessarily correlated with economic conditions in the locality [45]. As we did not have a direct measure of environmental expenses, we used the proxy of educational expenses, because at least part of each municipality's environmental activity is directed towards environmental educational activity that is added to the conventional curriculum required by the government.

Population density: Population density was used in previous studies as an additional indicator of the intensity of environmental problems [46]. As population density grows, environmental problems become more intense. In our study, industrial air pollution poses a larger risk when population density is higher. We used the number of residents per $\mathrm{km}^{2}$ for each locality in Israel, as computed and periodically updated by the CBS (Table 1).

\section{Results and Discussion}

For testing the indirect effects of NGO activity as well as CM on SLAB, we used AMOS 21.1 to test two alternative SEM models, one with mediation and another with direct relationship between all independent variables and SLAB. As our dependent variable is not normally distributed, we used Bayesian SEM to account for nonnormal distribution (Figure 1).

\begin{tabular}{|l|c|c|c|c|}
\hline Variable & Mean & Std. & Min. & Max \\
\hline Municipal Regulation Stringency (SLAB) & 2.491 & 2.159 & 0 & 9 \\
\hline SER & 5.20 & 2.091 & 1 & 10 \\
\hline NGOs Activity & 0.737 & 0.441 & 0 & 1 \\
\hline CM & 1.697 & 1.170 & 0 & 5 \\
\hline Env. Unit & 0.663 & 0.474 & 0 & 1 \\
\hline Perceived Risk & 0.467 & 0.500 & 0 & 1 \\
\hline Density & 3226.886 & 3405.596 & 74 & 21638 \\
\hline Educational Expenses & 0.236 & 0.068 & 0.09 & 0.45 \\
\hline Number of Facilities & 7.780 & 14.692 & 0 & 72 \\
\hline
\end{tabular}

Table 1: Independent and dependent variables: descriptive statistics.

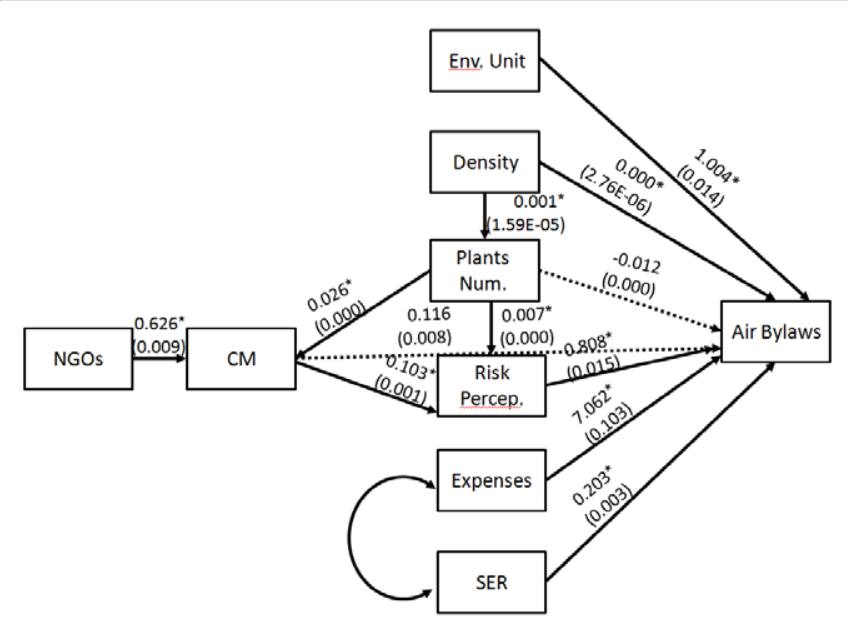

Figure 1: Model 1-Bayesian SEM with Risk Perception as an Explanatory Value. Regression Weight Means (standard error in parentheses) are presented. ${ }^{*}$ indicates that the connections are significant as 0 is not between $95 \%$ lower bound and $95 \%$ upper bound values. 
In model 1 we assume a direct effect of both perceived risk, objective risk and CM on SLAB in addition to the other independent variables, which we used as controls (environmental unit, socioeconomic conditions, expenses for education, population density). We also tested for the indirect effect of the objective risk indicator through its effect on the perceived risk. We further tested for the indirect effect of $\mathrm{CM}$ on SLAB through its effect on risk perception and an indirect effect of NGO activity on risk perception through its effect on CM. In this model all independent variables significantly affect SLAB except for two non-significant correlations. The analysis suggests that objective risk and CM did not affect SLAB directly. But both variables had a significant mediation affect. Bootstrap estimation for the indirect effect of CM on air bylaws is significant $(\mathrm{p}=0.028)$. The indirect effect size is 0.0888 . Bootstrap estimation for the indirect effect of NGOs on risk perception is significant $(\mathrm{p}=0.006)$. The indirect effect size is 0.066 .

Hence, municipalities more likely to enact stringent environmental bylaws are those with an environmental unit in place, higher socioeconomic ranking, and larger portions of total expenses for education, lower population density and local officials who perceive industry as a risk to air quality. Officials are more likely to perceive the industrial sector as a cause of air pollution when there are more industrial facilities in the locality and the municipality has a higher level of CM. When NGO activity is more apparent and the number of industrial facilities is higher, the locality is more likely to have a higher level of CM. Municipalities will use their regulatory power to increase their regulatory demands regarding air pollution from the industrial sector when they perceive the industrial sector as a risk to air quality. These results show that the perceived risk is affected not only by the actual number of industrial facilities that are sources of air pollution, but also by the degree of CM and the involvement of NGOs in the policy processes.

The mediation model (Model 1) was compared to a "test" model (Model 2) in which no mediation between the parameters was assumed to exist (Figure 2).

In model 2, we assume a direct effect of all the independent variables on SLAB without any mediation. In this model, risk indicators as well

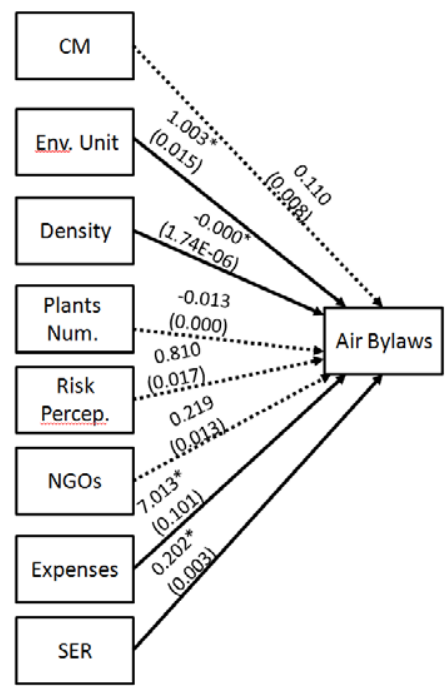

Figure 2: Model 2-Bayesian SEM with Number of Polluting Facilities as an Explanatory Value. Regression Weight Means (standard error in parentheses) are presented. *indicates that the connections are significant as 0 is not between 95\% lower bound and $95 \%$ upper bound values.

\begin{tabular}{|l|l|l|l|l|l|l|l|l|}
\hline \multicolumn{7}{|c|}{$\begin{array}{l}\text { Validation parameters. } \\
\text { Recommended values in brackets }\end{array}$} \\
\hline & $\mathbf{C}_{\text {min }}$ & df & $\begin{array}{l}\mathbf{C}_{\text {min }} \text { /df } \\
(<2)\end{array}$ & $\begin{array}{l}\text { CFI } \\
(>\mathbf{0 . 9 5 )}\end{array}$ & $\begin{array}{l}\text { RMSEA } \\
(<\mathbf{0 . 1 0 )}\end{array}$ & AIC & ECVI \\
\hline Mediation Model & 26.494 & 23 & 1.152 & 0.953 & 0.035 & 88.494 & 0.731 \\
\hline Non-Mediation Model & 28.985 & 21 & 0.114 & 0.892 & 0.056 & 94.985 & 0.785 \\
\hline
\end{tabular}

Table 2: Statistical Analysis (SEM) of the Structural Relationship Explaining Stringent Air Bylaws-a Comparison between Objective Risk Model, Subjective Risk Model and Non-Structural Model.

as CM and NGO activity don't significantly affect SLAB.

Table 2 represents different parameters of the models. As the models are non-nested (they differ in the explanatory variables) we use the ECVI and AIC to compare the models: the lower these parameters, the better the model. AIC and ECVI both show that the better model is the mediation model, as both values are lower. The comparison of the models supports our hypotheses (Table 2).

\section{Implications and Recommendations}

This paper sought to unravel factors that explain differences in SLAB at the local level, and especially why municipal officials choose race to the top when race to the bottom is legally enabled. We focus on two major explanatory variables: the role of perceived risk and $\mathrm{CM}$. Thus our study contributes to the thin extant literature on the role of municipalities in addressing environmental problems that are not necessarily GHG related. The paper constructs a model of factors affecting stringent environmental regulation and contributes to research regarding the role of problem severity [17] and CM, $[15,16]$ in explaining environmental policy outputs.

Results from our comparative analysis suggest two main insights that increase our understanding of the observed differences in SLAB. First, in line with previous research that stressed the importance of the perceptions of policy makers in determining policy outcomes [10], our study highlights the importance of policy makers' risk perceptions in determining policy outcomes. Our research presents initial evidence that local officials' risk perceptions better reflect policy outputs than do objective risk indicators. Hence, this study also extends previous inconclusive research on the matching perspective. It addresses the usefulness of incorporating policymaking officials' risk perceptions in the attempt to explain the relationship and often gaps between objective environmental indicators and policy-making. Still, further investigation should be addressed to the disconnection between objective and subjective risk measures, analyzing what constitutes this gap and how it can be minimized.

Second, our research points to the important role CM has on policy outputs. Local officials are more likely to see potential environmental problems as a threat to their locality and to act upon it when they operate CM. One way in which this may occur is through stakeholders' perceptions, mainly those of green NGOs, being better reflected in the ultimate policy outputs when CM is in place. While other actors may have various ways of getting through to the policy makers, as voters, residents and tax payers, NGOs are unique in the sense that they are external actors to the locality. Hence, CM seems to present NGOs with a way of delivering their ideas and agendas and influencing policy makers.

This study extends previous research on CM in several important ways. First, it addresses a lacuna in previous research - the paucity Michael [47,48] contrasted to most studies that focus on processes [49]. Second, in a research field characterized mainly by case studies, our 
Citation: Kerret D, Menahem G, Frishberg S (2015) The Role of Risk Perception and Collaborative Management in Explaining Stringent Municipal Regulations - The Israeli Air Pollution Case Study. Review Pub Administration Manag 3: 157. doi:10.4172/2315-7844.1000157

study advances research by offering a relatively large $\mathrm{N}$ study $[48,50]$. The study extends the very small number of non-US studies regarding environmental outputs in municipalities [9].

However, while this paper presents a conceptual model of the determinants of SLAB, it can only support the correlation between the variables, as it is cross-sectional research. Yet we suggest that conducting such cross-sectional research on these issues makes theoretical and practical sense. On the theoretical side, we suggest policy is not made in a vacuum. At each point in time prior legislation creates the policy context and the organizational culture in which the organization is working and individuals' perceptions are shaped. In turn, such perceptions relate to the continuous process of local rule making. Hence the causality between perceptions and rule making resembles a virtuous circle in which feedback mechanism play an important role. Hence, we expect that at each point in time we measure we will find a positive correlation between perceptions and rule making.

Similar interpretations have been suggested where social processes are complex. For example, Holmberg et al. suggest a parallel approach to the complex relationship between quality of government and economic growth [51] they claim that although significant relationships can be found between QoG and economic growth, care should be taken in interpreting these results. They suggest that one interpretation of the result could be that the causality between economic growth and QoG resembles a "virtuous circle" in which feedback mechanisms play an important role.

On the practical side, it has to be remembered that attempts to follow a unidirectional causality through longitudinal studies in large $\mathrm{N}$ studies require investigating in advance unspecified categories of office holders in the hope that they will be involved in the future in local rule making. This may be possible only in very limited cases and numbers.

Still, further research should follow risk indicators as well as risk perceptions and new bylaws over time. Furthermore, investigation should extend to other fields of local regulation and other environmental policy outputs. In addition, the current study focused on risk perception and the role of $\mathrm{CM}$ in influencing risk perceptions; further research is required to unravel the determinants of CM.

Based on an empirical study on a relatively large $\mathrm{N}$ sample, our findings offer important policy implications.

First: Sufficient research has accumulated regarding promising ways to establish and manage collaborative processes [52]. Demonstrating the usefulness of these practices for advancing environmental outputs should advance the transformation of academic knowledge about managing collaborations into practical instructions for moving to CM.

Second: An important path of influence for NGOs is through participating in and affecting the policymaking process. Hence, if NGOs' goal is to advance regulatory requirements for industrial facilities they should aim for CM. NGOs should consider the important role of collaborative forums as a path to influence policy when they consider their strategic actions. Furthermore, collaborative practices may be developed so that they can be introduced into policymaking processes.

\section{Acknowledgement}

The authors thank Dr. Avi Gottlieb for his most valuable contribution in design of the Local Municipalities survey; Sharon Malki, Bian Magala, and Gal Talit for their valuable contributions in implementation of the survey; and Eyal Bar-Haim, Adi Moreno, Carmel Blank and Renana Shvartzvald for their assistance in the statistical analysis and their helpful comments and insights. Especially warm gratitude is expressed to all the respondents from local municipalities in Israel; and finally, to the Hartog School of Government and Policy, Tel-Aviv University, to the Ford Foundation Israel Fund and to the Citizens' Empowerment Center in Israel for their assistance in funding this research.

\section{References}

1. Gerber BJ, Teske P (2000) Regulatory policymaking in the American states A review of theories and evidence. Political Research Quarterly 53: 849-886.

2. Konisky DM, Woods ND (2012) Measuring State Environmental Policy. Review of Policy Research 29: 544-569.

3. Owens K, Zimmerman C (2013) Local Governance Versus Centralization Connecticut Wetlands Governance as a Model. Review of Policy Research 30: 629-656.

4. Potoski M, Woods ND (2002) Dimensions of State Environmental Policies. Policy Studies Journal 30: 208-226.

5. Wang XH, Hawkins CV, Lebredo N, Berman EM (2012) Capacity to Sustain Sustainability A Study of US Cities. Public Administration Review 72: 841-853.

6. Mazmanian DA, Jurewitz J, NelsonH T (2013) The Paradox of "Acting Globally While Thinking Locally" Discordance in Climate Change Adaption Policy. The Journal of Environment and Development

7. Tang Z, Brody SD, Quinn C, Chang L, Wei T (2010) Moving from agenda to action evaluating local climate change action plans. Journal of Environmental Planning and Management 53: 41-62.

8. Zahran S, Grover H, Brody SD, Vedlitz A (2008) Risk, Stress, and Capacity Urban affairs review 43: 447-474.

9. Kim DR (2011) Do local policy networks deter the race to the bottom in environmental regulation? The case of South Korea. Environment and Planning-Part C 29: 1037-1053

10. Konisky DM (2008) Regulator attitudes and the environmental race to the bottom argument. Journal of Public Administration Research and Theory 18 321-344.

11. Meyer SM, Konisky DM (2007) Local institutions and environmental outcomes Evidence from wetlands protection in massachusetts. Policy Studies Journal 35: 481-502.

12. Kraft ME, Stephan M, Abel TD (2011) Coming Clean Information Disclosure and Environmental Performance.The MIT Press, Cambridge, Massachusetts.

13. Agranoff R, McGuire M (2004) Collaborative public management New strategies for local governments.Georgetown University Press

14. O'Toole LJ, Meier kJ, Nicholson-Crotty S (2005) Managing upward, downward and outward Networks hierarchical relationships and performance. Public Management Review 7: 45-68.

15. Mazmanian DA, Kraft M E (2009) Toward sustainable communities Transition and transformations in environmental policy. MIT Press

16. McGuire M, Silvia C (2010) The effect of problem severity managerial and organizational capacity and agency structure on intergovernmental collaboration Evidence from local emergency management. Public Administration Review 70: $279-288$

17. Sparrevik M, Ellen GJ, Duijn M (2011) Evaluation of Factors Affecting Stakeholder Risk Perception of Contaminated Sediment Disposal in Oslo Harbor. Environmental Science Technology 45: 118-124.

18. Meyer SM, Konisky DM (2007) Adopting local environmental institutionsEnvironmental need and economic constraints. Political Research Quarterly 60: 3-16.

19. Fischer F (2000) Citizens, experts, and the environment the politics of local knowledge. Duke University Press.

20. Dery D (1984) Problem definition in policy analysis.University Press of Kansas Lawrence, KS.

21. Stone DA (1988) Policy paradox and political reason .Scott Foresman Glenview IL 
Citation: Kerret D, Menahem G, Frishberg S (2015) The Role of Risk Perception and Collaborative Management in Explaining Stringent Municipal Regulations - The Israeli Air Pollution Case Study. Review Pub Administration Manag 3: 157. doi:10.4172/2315-7844.1000157

22. Stone DA (1989) Causal stories and the formation of policy agendas. Political science quarterly 104: 281-300.

23. Rochefort DA, Cobb RW (1993) Problem definition agenda access and policy choice. Policy Studies Journal 21: 56-71.

24. Schon DA (1995) Frame Reflection Toward The Resolution Of Intractrable Policy Controversies. Basic Books

25. Schram SF, Soss J (2001) Success stories Welfare reform, policy discourse and the politics of research.The Annals of the American Academy of Political and Social Science 577: 49-65.

26. Stone DA (1997) Policy paradox The art of political decision making.WW Norton New York

27. Yanow D (1996) American ethnogenesis and public administration. Administration and Society 27: 483-509.

28. Menahem G (1991) Public Policy and Political Interpretations of Socioeconomic Environments. International Journal of Sociology and Social Policy 11: 37-61.

29. Radin B (2006) Challenging the performance movement Accountability complexity and democratic values. Georgetown University Press

30. Engel KH (1996) State environmental standard-setting: is there a race and is it to the bottom. Hastings LJ 48: 271.

31. Risse T (2000) “ Let's Argue!" Communicative action in world politics. International Organization 54: 1-40.

32. Schmidt VA, Radaelli C M (2004) Policy change and discourse in Europe Conceptual and methodological issues. West European Politics 27: 183-210.

33. Fischer F (2009) Democracy and Expertise Reorienting Policy Inquiry Reorienting Policy Inquiry. OUP Oxford.

34. Kerret D, Menahem G (2016) Many Hands Make Light Work The Role of Collaborative Management in Improving Environmental Information Management by Local Authorities. International Journal of Public Administration 19.

35. Portney K (2005) Civic engagement and sustainable cities in the United States. Public Administration Review 65: 579-591.

36. Portney KE, Berry JM (2010) Participation and the Pursuit of Sustainability in US Cities. Urban affairs review 46: 119-139.

37. Kerret D (2008) ISO 14001 as an Environmental Capacity Building ToolVariations among Nations. Environmental Science Technology 42: 2773-2779.

38. Kerret D, Menahem G, Sagi R (2010) Effects of the Design of Environmental Disclosure Regulation on Information Provision The Case of Israeli Securities
Regulation. Environmental Science and Technology 44: 8022-8029.

39. Kerret D, Tal A (2005) Green Wash or Green Gain? Predicting the Success and Evaluating the Effectiveness of Environmental Voluntary Agreements. Penn State Environmental Law Journal 14: 31.

40. Rosen-Zvi I (Forthcoming) The Clean Air Act Between Centralization and Decentralization Hukim.

41. O'Toole LJ, Meier KJ (1999) Modeling the impact of public management Implications of structural context. Journal of Public Administration Research and Theory 9: 505-526.

42. Agranoff R (2006) Inside collaborative networks Ten lessons for public managers. Public Administration Review 66: 56-65.

43. Lubell M, Feiock R, Handy S, Susan L (2009) City adoption of environmentally sustainable policies in California's Central Valley. Journal of the American Planning Association 75: 293-308.

44. Lubell M, Feiock RC, De La Cruz EER (2009) Local institutions and the politics of urban growth. American Journal of Political Science 53: 649-665.

45. Katan J (1997) Decentralization in personal welfare services a comparative analysis of the Tel-Aviv metropolitan area. In: Nachmias D, Menahem G (eds.) Tel-Aviv Studies, Social Processes and Public Policy 2: 81-104

46. Tang Z, Brody SD, Li R, Quinn C, Zhao N (2011) Examining locally driven climate change policy efforts in three Pacific states. Ocean and Coastal Management 54: 415-426.

47. McGuire M, Agranoff R (2011) The Limitations of public management networks. Public Administration 89: 265-284.

48. Muñoz Erickson TA, Aguilar-González B, Loeser MR, Sisk TD (2010) A framework to evaluate ecological and social outcomes of collaborative management lessons from implementation with a Northern Arizona collaborative group. Environmental management 45:132-144 .

49. Koontz TM, Thomas CW (2006) What Do We Know and Need to Know about the Environmental Outcomes of Collaborative Management? Public Administration Review 66: 111-121.

50. McGuire M (2006) Collaborative public management Assessing what we know and how we know it. Public Administration Review 66: 33-43.

51. Holmberg S, Rothstein B, Nasiritousi N (2009) Quality of government what you get. Annual Review of Political Science 12: 135-16.

52. Agranoff R (2012) Collaborating to Manage A Primer for the Public Sector Georgetown University Press. 